\title{
Nuclear localization signals, genetıc characterısatıon ana morphological study of wild type and 14 Arabidopsis mutant lines
}

\author{
Asaad M Mahmood ${ }^{1}, \operatorname{Jim}$ M Dunwell ${ }^{2}$ \\ ${ }^{1}$ Department of Biology, College of Education, University of Garmian, Kalar, KRG/Iraq \\ ${ }^{2}$ School of Biological Sciences, University of Reading, Reading, Berkshire, UK \\ Email: Asaad M Mahmood - asaad@garmian.edu.krd; \\ Jim M Dunwell- j.m.dunwell@reading.ac.uk
}

\begin{abstract}
$\underline{\text { Abstract }}$
2-oxoglutarate-dependent (2-OG) dioxygenases [2(OG)-dioxygenases] are distributed in a wide range of prokaryotes and eukaryotes, and are involved in many different important biological activities, for example biosynthesis of plant products including plant hormones and antioxidants, posttranslational modification, DNA/RNA damage repair and in certain organisms modulations of epigenetic modifications. These 2(OG) dioxygenase enzymes contain a characteristic iron (Fe)binding active site. To understand their role in modulating mechanisms against unfavourable conditions, the present study examined nuclear localization signal (NLS), genetic status, phenotypic patterns of 14 T-DNA mutants of Arabidopsis containing an insert in their (2-OG) dioxygenase genes. Results showed that predicted localizations of proteins encoded by respective genes varied according to four different methods used in this analysis; seven, three, one and one of them were predicted to be located in the nucleus according to the four methods, respectively. Moreover, genotypic analysis confirmed the homozygosity of plant(s) of nine of these mutant lines [N671573 (insert in At1g20270), N668172 (At1g68080), N652869 (At2g17720), N679576 (At3g06290), N678627 (At3g28490), N338446 (At4g35810), N683883 (At4g35820), N666896 (At5g18900), N598611 (At5g66060)] and phenotypic analysis including vegetative, siliques and seed characteristics of those plants showed different characteristics either within each mutant (homozygous and heterozygous), or between mutants and the WT.
\end{abstract}

\section{Introduction:}

2(OG)-dioxygenases are one of the most functionally diverse super-families of non-haem enzymes; they are distributed in a wide range of prokaryotes and eukaryotes, and are involved in many different important biological activities including biosynthesis of plant products and antibiotics, posttranslational modification, DNA/RNA damage repair and 
metabolism of lipids (Hewitson et al. 2005). For example, within plants one sub-class of these enzymes comprise anthocyanidin synthase, flavanone $3 \beta$-hydroxylase and flavonol synthase (Hausinger, 2015); these particular enzymes are responsible for biosynthesis of flavonoids, secondary products, which are ubiquitous in spermatophytic plants, and fulfil a multitude of physiological roles (Cheynier et al. 2013; Saito et al. 2013). These roles include adaptation to biotic and abiotic stresses in which flavonoids function in helping plants to cope with stress by modulating fertility and regulating the transport of auxin, an important plant hormone (Martens et al. 2010; Cheynier et al. 2013).

The localization of dioxygenase proteins in the nucleus may increase their possible contribution in epigenetic modifications in plants. The analysis of nuclear localization signal (NLS) is one means to predict the localization of particular proteins. A NLS consists of one or more short sequence(s) of amino acid which tags a protein to import it into the nucleus, mitochondria and plastids by cross-membrane transport. Such signals are composed of positively charged lysine and arginine residues located in peptides that are thought to bind their receptors and make loops or patches on the protein surface (Alberts et al. 2008). This binding mediates nuclear import of proteins, known as the karyopherins (Importins) (Jans et al. 2000). Through the importin $\alpha / \beta$ pathways, importin $\alpha$ works as an adaptor, so it links each cargo and importin $\beta 1$ and subsequently discriminates NLSs within the cargos (Lange et al. 2007).

The analysis of nuclear localization signals (NLS) is a useful tool to predict the intracellular location of a particular protein (Uji et al. 2009; Lee et al. 2012; Geilen and Böhmer, 2015). Any protein associated with the modification of nuclear DNA should by definition be active in the nucleus. There are some epigenetic changes such DNA methylation and histone modifications in nuclear DNA that are similar to those found in animals. Recent studies of cytosine methylation in selected animals determined the role of Ten Eleven Translocation (TET) enzymes (a particular type of 20G-dioxygenases) in producing a range of oxidised derivatives from 5-methyle cytosine $(5 \mathrm{mC})$. These enzymes contain a dioxygenase domain with the characteristic Fe-binding active site motif $\mathrm{HXDXnH}$ (where $\mathrm{X}$ is any amino acid). The following sequences of a subset of 14 Arabidopsis 2(OG)-dioxygenase proteins, were selected as being most similar to TET proteins, and the present study compared the nuclear localisation signal, genetic (homozygous and heterozygous) status and phenotypic characteristics including plant vigour, embryo and seed shapes of T-DNA lines 
that contain an insert in the 14 genes encoding these proteins (Figure 1. 1). Such information formed the foundation for subsequent parts of the project that measured the amount of ascorbate in selected mutant lines and examined aspects of the response of 2(OG)dioxygenase genes to different concentrations of $2 \mathrm{HG}$ and to different conditions of $\mathrm{Fe}$ deficiency.

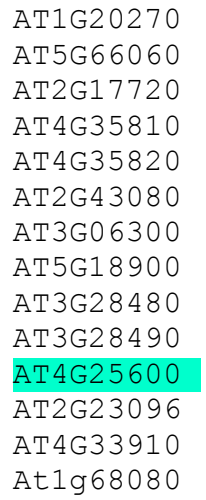

AT1G20270 AT5G66060 AT2G17720 AT4G35810 AT 4G35820 AT2G43080 AT3G06300 AT5G18900 AT3G28480 AT3G2 8490 AT 4G25600 AT2G23096 AT4G33910 At1g68080

AT1G20270 AT5G66060 AT2G17720 AT 4G35810 AT 4 G35820 AT2G43080 AT3G06300 AT5G18900 AT3G28480 AT3G28490 AT 4G25600 AT2G23096 AT4G33910 At 1 g68080
DHGEGLQVLHYEAGQKYEPHYDYFVDEFNTKNGGQRMATMLMYLSDVEEGGETVFPAANM 217 EHGEGLQVLHYEIGQKYEPHYDYFMDEYNTRNGGQRIATVLMYLSDVEEGGETVFPAAKG 219 ENGEGLQVLHYQVGQKYEPHYDYFLDEFNTKNGGQRIATVLMYLSDVDDGGETVFPAARG 221 ENGEGLQVLHYEVGQRYEPHHDYFFDEFNVRKGGQRIATVLMYLSDVDEGGETVFPAAKG 221 ENGETLQVINYEVGQKFEPHFD----------GFQRIATVLMYLSDVDKGGETVFPEAKG 227 ENGELIQVLRYEPQQFYKPHHDYFADTFNLKRGGQRVATMLMYLTDDVEGGETYFPLAGD 220 ENGEDLQVLRYEHGQKYDAHFDYFHDKVNIARGGHRIATVLLYLSNVTKGGETVFPDAQE 179 ENGEDIOVLRYEHGQKYDAHFDYFHDKVNIVRGGHRMATI LMYLSNVTKGGETVFPDAEI 178 ENGESMQ I LHYENGQKYEPHFDYFHDQANLELGGHRIATVLMYLSNVEKGGETVFPMWKG 197 ENGEALQILHYENGQKYDPHFDYFYDKKALELGGHRIATVLMYLSNVTKGGETVFPNWKG 174 ENGGSIKVRSYTS-EKSGKKLDYFGEEPSSVLHESLLATVVLYLSNTTQGGELLFPNSEM 182 DYYESFNILRYQLGQKYDSHYDAFHSAEYGPLISQRVVTFLLFLSSVEEGGETMFPEENG 209 SHGES FNILRYELGQKYDSHYDVFNPTEYGPQSSQRIASELLYLSDVEEGGETMFPFENG 222 EFTG---LISWCKGAS IGWHSD--DNRSYLKQRDFAAVCYLNSYEKDFIGG--LFRFQSG 135

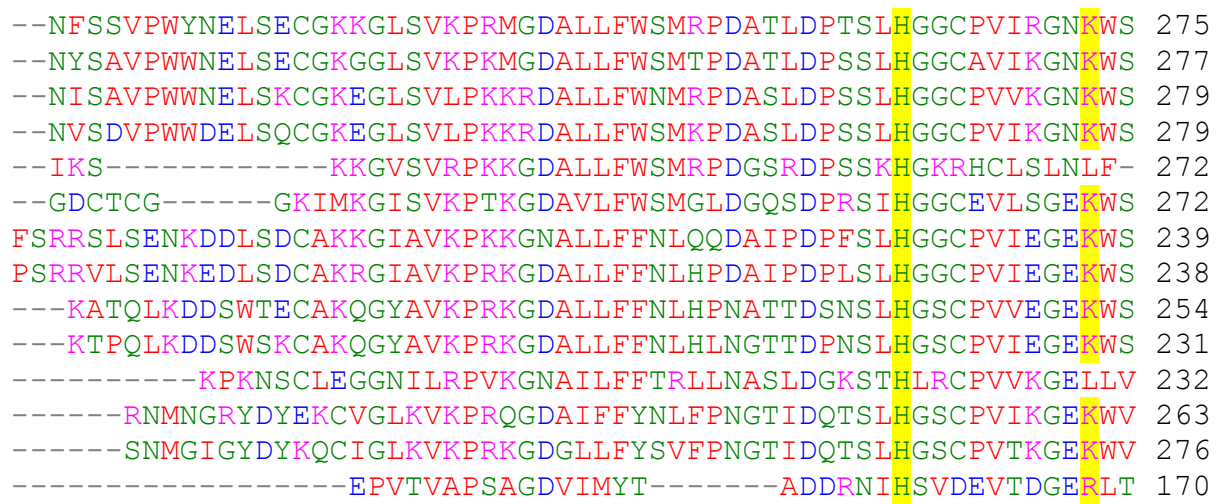

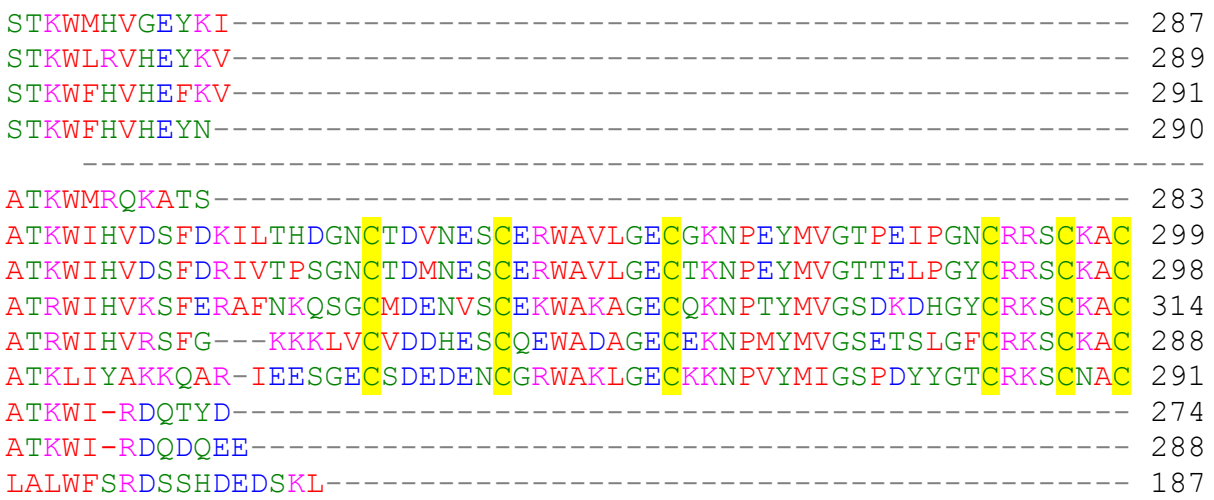

Figure 1. 1. Clustal W (http://www.ebi.ac.uk/Tools/msa/clustalw2/) alignment of selected dioxygenase proteins from Arabidopsis thaliana (courtesy of JM Dunwell) 


\section{Material and methods:}

\subsection{Nuclear Localization Signal}

In order to predict the intracellular localisation of selected dioxygenase proteins in the 14 Arabidopsis mutant lines, their protein sequences were analysed using Support Vector Machine-based localization predictor (AtSuP) programme which has seven possible categories, Nucleus, Mitochondrion, Chloroplast, Cytoplasm, Plasma membrane, Golgi apparatus and Plasma membrane. The software analysis included four options namely Amino acid composition-based, Dipeptide composition-based, N-Center-C terminal based and Best hybrid-based classifier (AA+PSSM+N-Center-C+PSI-BLAST).

\subsection{Seed germination under controlled environment}

To determine the phenotype characteristics of WT and mutants, stratified seeds were grown and germinated in $6.5 \times 6 \mathrm{~cm}$ mini-flower pots ( 2 seeds in each pot) containing potting growing medium (supplied from www.william.sinclair.co.uk) and topped with vermiculite, six pots for WT and each mutant were placed in a tray and maintained under controlled environmental conditions at $22{ }^{\circ} \mathrm{C}$ and $60 \%$ Relative Humidity (RH) with a day/night cycle of $16 / 8 \mathrm{~h}$ (at $100 \mu \mathrm{mol} \mathrm{m}^{-2} \mathrm{~s}^{-1}$ light intensity) in the University of Reading growth chambers (Fitotron plant growth chambers, Weiss Gallenkamp, UK). In order to avoid cross pollination each plant was covered with a transparent flower sleeve (Zwapak, Holland) prior to flowering.

\subsection{Confirmation of genetic status of mutant lines}

Genomic DNA of mutant lines (5 plants/mutant line) was extracted according to the DNeasy Plant Mini kit protocol (http://www.qiagen.com). $2 \mu$ l genomic DNA for each plant/line was added to $23 \mu \mathrm{l} \mathrm{PCR} \mathrm{mixture} \mathrm{containing} 12.5 \mu \mathrm{l} 2 \mathrm{X}$ BioMix PCR master mix (Bioline, UK,), $0.75 \mu \mathrm{l}$ of $0.3 \mu \mathrm{M}$ each forward primer (or left border primer which LBb1.3 5'ATTTTGCCGATTTCGGAAC-3', NR80 5'-GCTGATACAAAAACAAAACAACGA-3' and LB1 5'-GCC TTT TCA GAA -ATG GAT AAA TAG CCT TGC TTC C-3' were used with SALK, GK and SAIL insertions respectively) and reverse primer, and $9 \mu \mathrm{l}$ TE water. PCR in a GeneAmp PCR system 9700 (Applied Biosystems) was conducted for each reaction mixture, the 
amplification condition was one cycle of $95^{\circ} \mathrm{C}$ for $30 \mathrm{~s}$, then 35 cycles of $95^{\circ} \mathrm{C}$ for $30 \mathrm{~s}, 56^{\circ} \mathrm{C}$ for $45 \mathrm{~s}$, and $72^{\circ} \mathrm{C}$ for $90 \mathrm{~s}$ at the transition speed S-9 and finally one cycle of $74^{\circ} \mathrm{C}$ for $5 \mathrm{~min}$. The total amplification time was $102 \mathrm{~min}$. The PCR products (9-10 $\mu$ l of each) were separated by electrophoresis in $1 \%$ agarose gels supplemented with ethidium bromide $3 \mu \mathrm{l} / 70 \mathrm{ml}$. Thereafter, in order to visualize the gel, it was placed on a GelDoc-It ${ }^{\text {TS2 Imager (UVP) }}$ followed by capturing a clear picture through GeneSnap (version 6.00.19) system (SynGene, UK) and the genetic status was recognized according to the following Figure 2. 1.

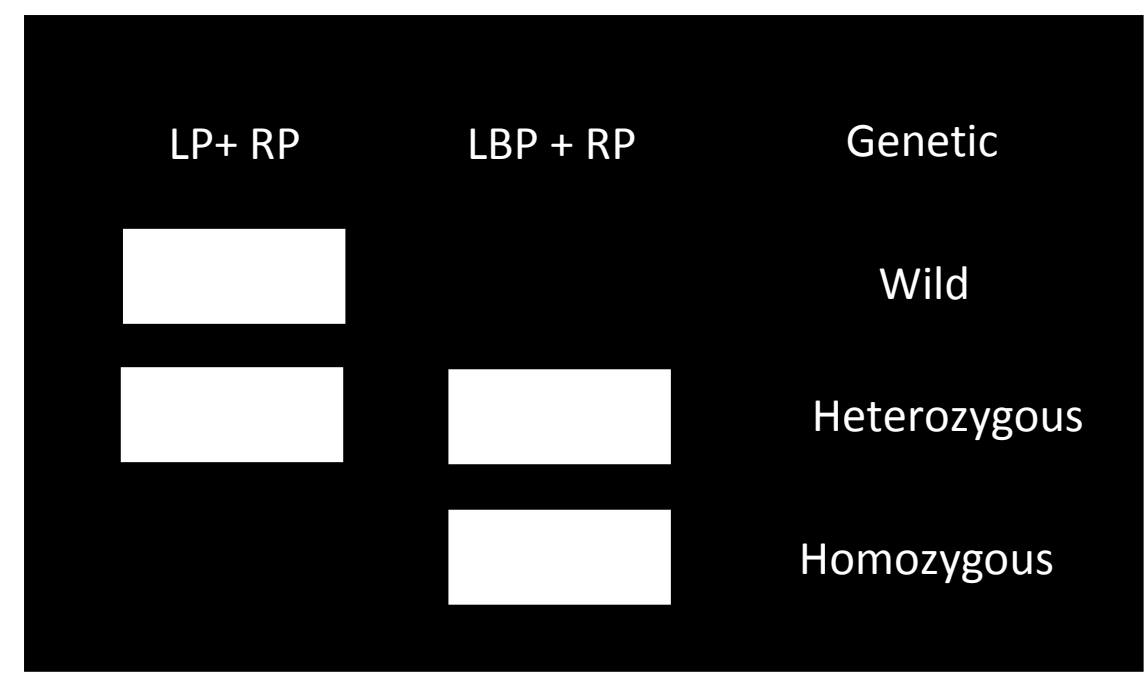

Figure 2. 1. Protocol for SALK T-DNA design primer. LP = Left or forward primer, RP = Right or Reverse primer and LBP = Left border primer.

\subsection{Phenotypic measurements}

Germination of mutant seeds was determined as a percentage rate (Chaudary et al. 2001). In order to obtain segregation or uniform patterns of mutant lines, pictures of plants at different stages of vegetative development from germination to seeding were selected and recorded. All plants from each family (NASC code) were compared together. Observation and recording of siliques and seeds under a dissecting microscope provided other parameters that were used to identify the normalities and abnormalities of silique growth (growth of embryo/seeds inside the silique), seed sizes and seed shapes of each mutant line. Phenotypic aspects were visualized using a Leica MZ95 stereomicroscope (Leica Microsystems, CH-9435, Heerbrugg) and captured using a Leica DFC290 (an integrated digital camera with Leica MZ95 and Leica application suite). 


\section{Results}

\subsection{Prediction of Nuclear Localization Signal (NLS)}

NLSs were found to show different patterns of amino acid residues (Table 3. 1). The analysis predicted the presence of NLS to the nucleus for proteins encoded by seven genes namely At1g68080, At2g17720, At3g06300, At3g28480, At4g25600, At4g35810 and At4g35820. Similarly, the dipeptide composition (sequence-order) based method predicted that proteins encoded by three genes At1g68080, At3g28480 and At4g25600 were likely to be transported into in the nucleus. However, only the dioxygenase protein encoded by the At1g68080 gene was predicted to be located in the nucleus when analysed by N-Center-C terminal (3-parts) based. In the similar way, a protein encoded by a different gene At4g35810 was predicted to occur in the nucleus with AA+NCC+PSI-BLAST+PSSM (best hybrid) based analysis. All other proteins were shown to be localised in the other organelles such as chloroplast and mitochondrion and or in an unknown location.

The At1g68080 protein is predicted to function in the nucleus according to the $\mathrm{N}$-Center-C terminal (3-parts) but its location is unknown according to the AA+NCC+PSI-BLAST+PSSM (best hybrid) based method.

A similar result was obtained with the protein encoded by the At4g35810 gene; it was predicted to be located in the nucleus based on the hybrid test and its location was unknown based on each of $\mathrm{N}$-Center-C terminal (3-parts) and Dipeptide composition (sequence-order) methods. 
Table 3. 1. NLS predictions of Arabidopsis thaliana depending on AtSubP bioinformatics software.

\begin{tabular}{|c|c|c|c|c|}
\hline \multirow{2}{*}{ Gene name } & \multicolumn{4}{|c|}{ AtSubP } \\
\hline & $\begin{array}{r}\text { Amino Acid composition } \\
\text { based SVM }\end{array}$ & $\begin{array}{l}\text { Dipeptide composition } \\
\text { (sequence-order) based }\end{array}$ & $\begin{array}{r}\mathrm{N}-\text { Center-C terminal (3- } \\
\text { parts) based }\end{array}$ & $\begin{array}{r}\mathrm{AA}+\mathrm{NCC}+\mathrm{PSI}-\mathrm{BLAST}+\mathrm{PSSM} \text { (best } \\
\text { hybrid) based }\end{array}$ \\
\hline At1g68080 & Nucleus & Nucleus & Nucleus & Unknown \\
\hline At2g17720 & Nucleus & Unknown & Unknown & Unknown \\
\hline At3g06300 & Nucleus & Unknown & Extracellular & Extracellular \\
\hline At3g28480 & Nucleus & Nucleus & Extracellular & Extracellular \\
\hline At4g25600 & Nucleus & Nucleus & Chloroplast & Chloroplast \\
\hline At4g35810 & Nucleus & Unknown & Unknown & Nucleus \\
\hline At4g35820 & Nucleus & Unknown & Mitochondrion & Unknown \\
\hline At2g23096 & Extracellular & Unknown & Extracellular & Extracellular \\
\hline At1g20270 & Chloroplast & Unknown & Mitochondrion & Mitochondrion \\
\hline At4g33910 & Chloroplast & Unknown & Mitochondrion & Unknown \\
\hline At5g18900 & Chloroplast & Unknown & Extracellular & Extracellular \\
\hline At5g66060 & Chloroplast & Unknown & Mitochondrion & Unknown \\
\hline At2g43080 & Unknown & Unknown & Extracellular & Extracellular \\
\hline At3g28490 & Unknown & Unknown & Extracellular & Extracellular \\
\hline Total & 7 & 3 & 1 & 1 \\
\hline
\end{tabular}

AtSubP= http://bioinfo3.noble.org/AtSubP/?dowhat=AtSubP

682 acadj@garmian.edu.krd $\quad$ Conference Paper (July, 2017)




\subsection{Molecular characterization of Arabidopsis mutant lines}

In Table 3. below, at least one homozygous plant was determined in each of nine mutant lines. On the (NASC) website, each of the N671573, N683883, N679576, N668172 and N678627 mutant lines are described as being homozygous. However, results showed segregation in these lines. Moreover, despite a clear band being detected with LP+RP in the fourth replicate of $\mathrm{N668172}$ mutant, no amplification was observed with LBP+RP primer sets; it appeared that there was no T-DNA insert in this plant and it should be considered as a WT. PCR confirmation represented in Figure 3. shows that in N652869, N338446, N666896 and N598611, which are described by NASC as being heterozygous, at least one homozygous plant was present. The identification of homozygous plant(s) within each mutant line allowed the generation of enough homozygous plants to permit further investigations in each line.

Table 3. 1. Identifications the genetic status of eight genes using basic PCR. $H=$ Homozygous, $T=$ Heterozygous and $\mathrm{WT}=$ Wild type, $\mathrm{R}=$ Replicate of plants of each mutant line.

\begin{tabular}{|c|c|c|c|c|c|c|c|}
\hline Gene & NASC code & R1 & R2 & R3 & R4 & R5 & $\begin{array}{c}\text { Number of } \\
\text { homozygous plants }\end{array}$ \\
\hline At1g20270 & N671573 & H & H & T & H & H & 4 \\
\hline At1g68080 & N668172 & H & T & - & WT & H & 2 \\
\hline At2g17720 & N652869 & H & T & T & T & H & 2 \\
\hline At3g06290 & N679576 & T & T & T & T & H & 1 \\
\hline At3g28490 & N678627 & H & H & T & H & T & 3 \\
\hline At4g35810 & N338446 & H & T & H & T & T & 2 \\
\hline At4g35820 & N683883 & H & H & H & H & T & 4 \\
\hline At5g18900 & N666896 & H & H & H & H & H & 5 \\
\hline
\end{tabular}




\begin{tabular}{|l|l|l|l|l|l|l|l|}
\hline At5g66060 & N598611 & T & T & H & T & H & 2 \\
\hline
\end{tabular}

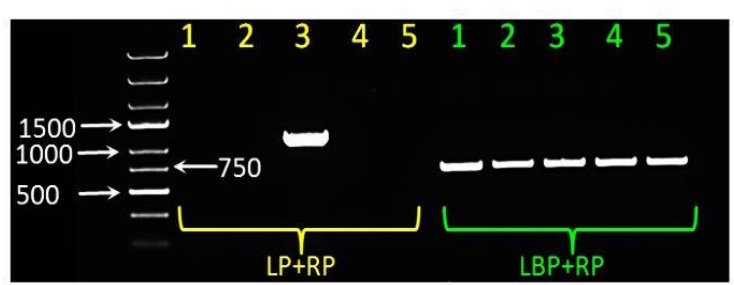

N671573 (At1g20270)

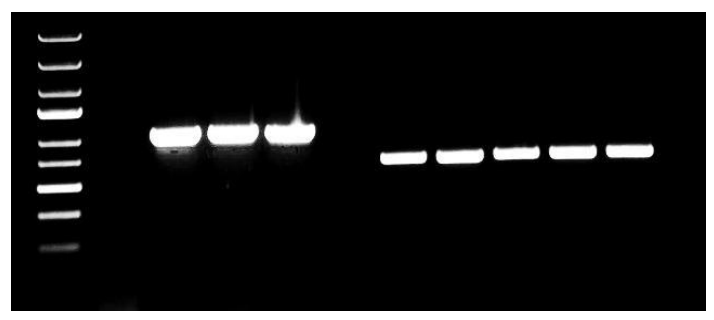

N652869 (At2g17720)

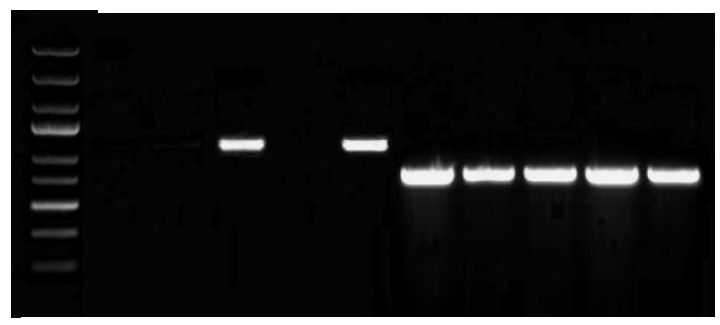

N678627 (At3g28490)

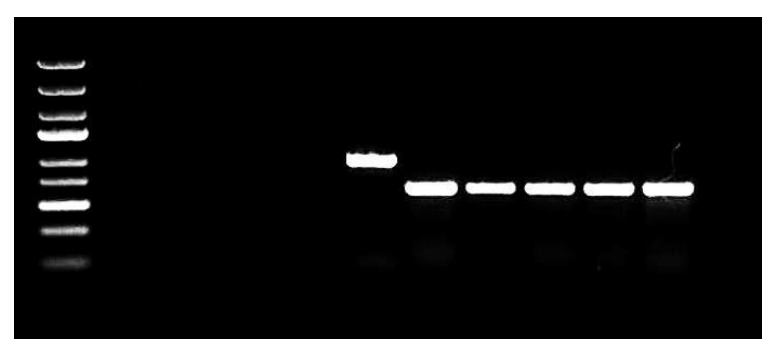

N683883 (At4g35820)

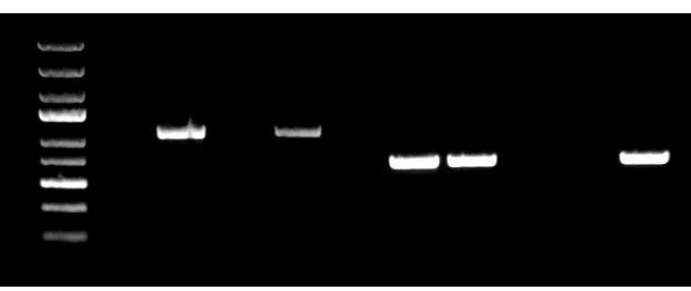

N668172 (At1g68080)

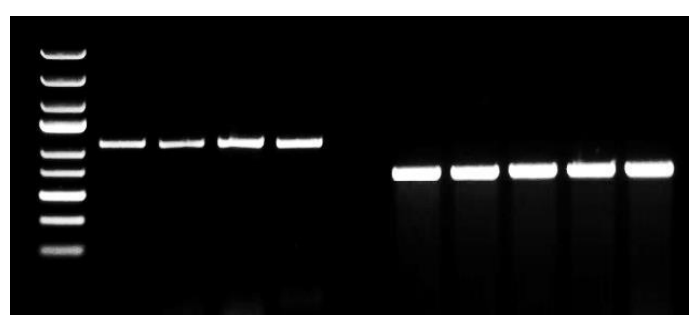

N679576 (At3g06290)

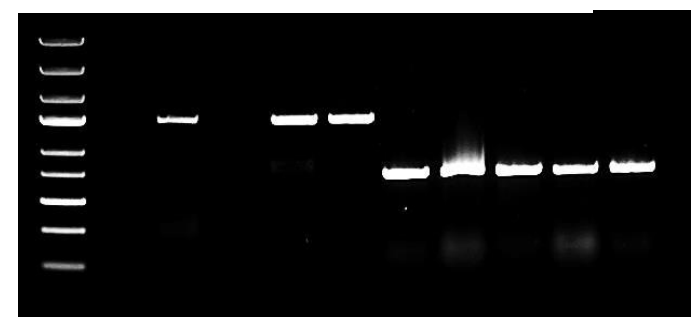

N338446 (At4g35810)

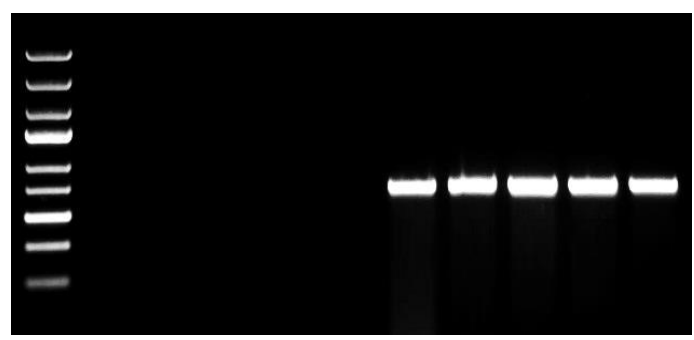

N666896 (At5g18900)

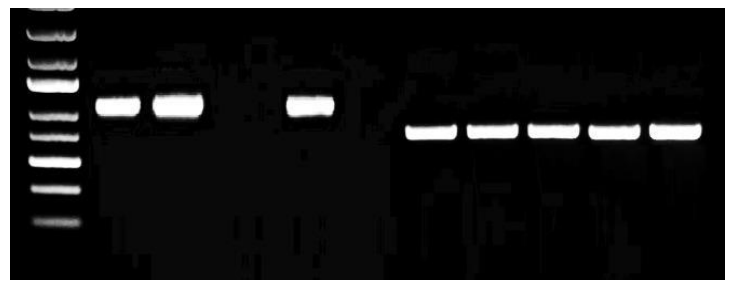

N598611 (At5g66060) 
Figure 3. 1. Confirmation of genetic status (Homozygous, Heterozygous or WT) of mutant lines using SALK TDNA design primer protocol.

\subsection{Morphological study of mutants}

An analysis was conducted on nine selected mutants to better understand the effect of T-DNA insertion on phenotypic characteristics including germination rates, characteristic of growth, silique and seed shapes. Results recorded from this study are described in Table 3. .

This study described the various phenotypic characteristics of nine mutant Arabidopsis plants under a controlled environment. As described above, observation of the various families of mutants showed that within some families there was plant to plant variation in terms of different phenotypes from germination to flowering and seed set. Seeds of the N671573 mutant showed a lower germination rate than the WT (70\% compared with 100 $\%)$, and slower germination (1d later in comparison to the WT and other mutants). Different plants of this mutant also varied in other aspects of vegetative growth; this was in line with the reduced level ( $84.5 \%$ ) of normal siliques. The variation in this line occurred despite the fact that it was described as being homozygous (according to NASC). Another line N668172 has an insert in chromosome 1 in the gene At1g68080. Generally, all plants of this mutant showed high germination rate (90\%), high normal growth (100\%), and similar morphology including plant height, normal silique and seed shapes, which suggests that this knockout did not affect the phenotype (for more detail about measurement of selected mutant lines, see Table A1 in the appendices).

Although N652869, which contains an insert in At2g17720, is described as being heterozygous, the results showed normal silique rates (98\%) and seeds (100\%) as well as a high rate of normal growth (100\%). Furthermore, the insert in line N679576 is present in At3g06290. Results from this line showed a low germination rate (50\%) and abnormalities at other growth stages such as $30.5 \%$ of abnormal siliques growth, which is the highest value that was recorded in this study. The mutant line N338446 that contains a T-DNA insertion in At4g35810 is described as being heterozygous (according to NASC). Despite a lower germination rate $(80 \%)$ in this mutant, all plantlets grew normally. Although variation in rates of vegetative growth between plants was noted, it mostly involved larger rosette diameter $(7.5 \mathrm{~cm})$ and much more vigour in comparison to the WT and other mutants. In all five selected siliques, the lack of an embryo or its abnormal growth (23\%) was recorded; these variations were also linked to differences in seed shapes (4.5\%). 
Table 3. 2. Characterization of mutant lines of Arabidopsis thaliana showing presumed genetic status and position of T-DNA insert (According to NASC) and features of vegetative growth, silique development and seed sizes (Based on experimental results).

\begin{tabular}{|c|c|c|c|c|c|c|c|c|c|c|c|}
\hline \multirow{3}{*}{ Gene ID } & \multicolumn{4}{|c|}{ NASC background information } & \multicolumn{7}{|c|}{ Present study results } \\
\hline & \multirow{2}{*}{ NASC code } & \multirow{2}{*}{$\begin{array}{l}\text { Homozygous } \\
\text { Line }\end{array}$} & \multirow{2}{*}{$\begin{array}{l}\text { Heterozygous } \\
\text { line }\end{array}$} & \multirow{2}{*}{$\begin{array}{l}\text { Position of } \\
\text { insert }\end{array}$} & \multirow{2}{*}{$\begin{array}{c}\text { Germination } \\
\text { Rates (\%) }\end{array}$} & \multirow{2}{*}{$\begin{array}{l}\text { Normal } \\
\text { growth of } \\
\text { Plantlets } \\
(\%)\end{array}$} & \multirow{2}{*}{$\begin{array}{c}\text { Phenotype } \\
\text { patterns }\end{array}$} & \multicolumn{2}{|c|}{ Siliques (\%) } & \multicolumn{2}{|c|}{$\begin{array}{c}\text { Seed } \\
\text { shapes }(\%)\end{array}$} \\
\hline & & & & & & & & $\mathrm{N}$ & $A$ & $N$ & $A$ \\
\hline Wild type & - & - & - & - & 100 & 100 & Similar & 100 & 0 & 100 & 0 \\
\hline At1g20270 & N671573 & $*$ & & $\begin{array}{l}7,021,373- \\
7,022,913\end{array}$ & 70 & 86 & Similar & 84.5 & 15.5 & 97.5 & 2.5 \\
\hline At1g68080 & N668172 & $*$ & & $\begin{array}{l}25,521,372- \\
25,522,903\end{array}$ & 90 & 100 & Similar & 90 & 10 & 97 & 3 \\
\hline At2g17720 & N652869 & & $*$ & $\begin{array}{l}7,704,595- \\
7,706,256\end{array}$ & 60 & 100 & Similar & 98 & 2 & 100 & 0 \\
\hline At3g06290 & N679576 & $*$ & & $\begin{array}{l}1,899,129- \\
1,907,303\end{array}$ & 50 & 100 & Similar & 69.5 & 30.5 & 95 & 5 \\
\hline At3g28490 & N678627 & & $*$ & $\begin{array}{l}10,680,280- \\
10,680,452\end{array}$ & 86 & 83 & Similar & 87 & 13 & 95 & 5 \\
\hline At4g35810 & N338446 & & $*$ & $\begin{array}{l}16,968,925- \\
16,970,509\end{array}$ & 80 & 100 & Varied & 77 & 23 & 95.5 & 4.5 \\
\hline At4g35820 & N683883 & $*$ & & $\begin{array}{l}16,971,225- \\
16,972,433\end{array}$ & 50 & 50 & Similar & 72 & 28 & 100 & 0 \\
\hline At5g18900 & N666896 & $*$ & & $\begin{array}{l}6,304,411- \\
6,306,168\end{array}$ & 100 & 100 & Similar & 95 & 5 & 100 & 0 \\
\hline At5g66060 & N598611 & & $*$ & $\begin{array}{l}26,436,707- \\
26,438,156 \\
\end{array}$ & 60 & 83 & Varied & 94 & 6 & 100 & 0 \\
\hline
\end{tabular}

Where: $-\mathrm{N}=$ Normal growth and $\mathrm{A}=\mathrm{Abnormal}$ growth 
Another mutant line (N598611) containing an insertion in the gene At5g66060 displayed interesting morphological characteristics. Results recorded from plants of this mutant showed differences in terms of a low germination rate $(60 \%)$ and higher growth rate $(83 \%)$. These results were in line with a high normal silique production and mature seed appearance ( $94 \%$ and $100 \%$ respectively). Generally, as illustrated in Figure 3. and Table 3. 3, greater rosette diameter $(7 \mathrm{~cm})$ was found in heterozygous plants compared with the WT $(4 \mathrm{~cm})$ and slower growth $(5 \mathrm{~cm})$ in homozygous plants of this mutant (N598611). However, the WT appeared to flower more rapidly (13 d vs. $15 \mathrm{~d}$ and 19d) than heterozygous and homozygous plants, respectively. This difference was associated with a high number of flowers (13) with the WT, compared to four and one flower(s) with each heterozygous and homozygous plant respectively.

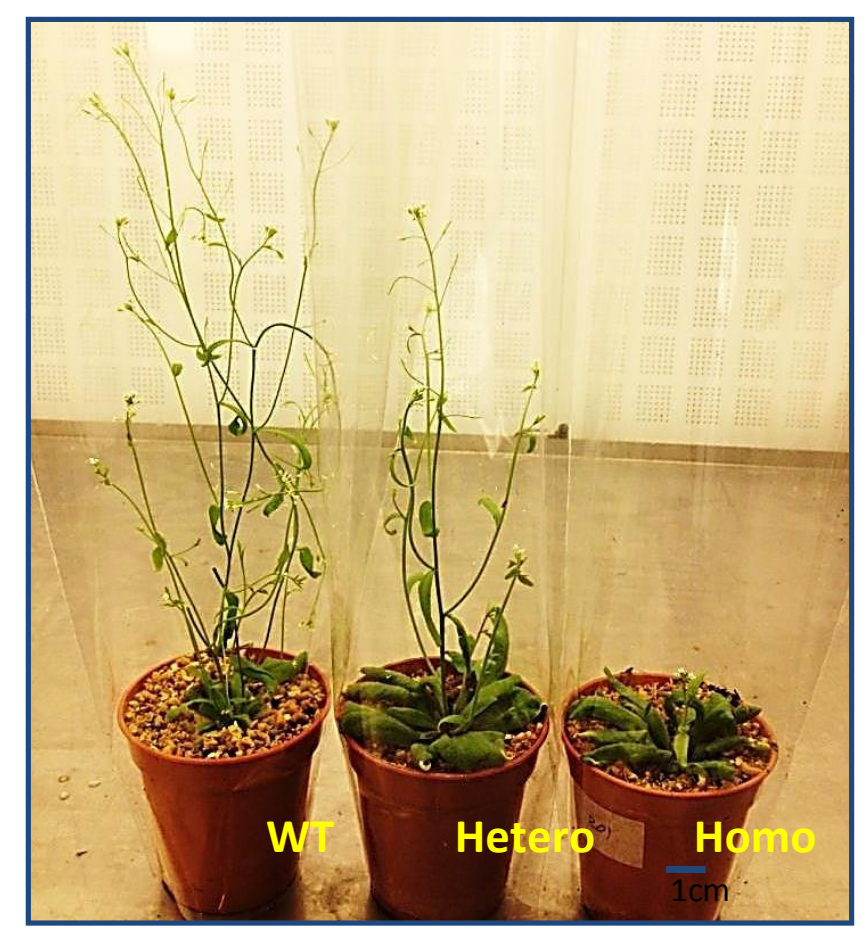

Figure 3. 2. Phenotypic comparison of WT plant with heterozygous and homozygous plants of N598611 mutant line 3 weeks after germination.

Table 3. 3. Comparison of phenotypic measurements of WT plant with heterozygous and homozygous plants (3 replicates for each genotype) of the N598611 mutant line.

\begin{tabular}{|r|c|c|c|}
\hline & WT & Heterozygous & Homozygous \\
\hline Rosette diameter $(\mathbf{c m})$ & 4 & 7 & 5 \\
\hline No. of leaves & 10 & 12 & 12 \\
\hline Plant height $(\mathbf{c m})$ & 18 & 14 & 2 \\
\hline Flowering time (d) & 13 & 15 & 1 \\
\hline No. of flowers & 13 & 4 & \\
\hline
\end{tabular}




\section{Discussion}

\subsection{Nuclear localisation signal (NLS)}

Results from this analysis showed differences between methods used to predict the localization of respective proteins; these differences may result from the different principles of the different analytical methods, in that they test protein motifs depending on the amino acid compositions, dipeptide compositions and N, C-terminus details or on a combination of these.

These results might be useful in understanding the functional variety of proteins involved in cytosine methylation and demethylation and in regulating responses against stress conditions, including the exact role of each of the target proteins and their regulatory signals. A relevant review by Grandperret et al. (2014) stated that a specific nuclear signal transduction regulates expression of specific gene sets, which subsequently leads to an appropriate response to stress conditions. Interestingly, components of these pathways are subjected to post-translational modifications as well as epigenetic changes. Nuclear protein acetylation and/or deacetylation are important post-translational modifications that play major roles in the regulation of gene expression (Chen and Tian, 2007).

In light of this, in order to understand the precise localisation of those proteins in response to unfavourable conditions, it would be important experimentally to study the subcellular localisation of respective proteins, for example with techniques using green fluorescent protein (GFP) (Etchegaray et al. 2015). These techniques will be useful to understand mechanisms that modulate gene expression under different environmental conditions.

\subsection{Confirmation of genetic status of mutant lines}

The confirmation of genetic status is an important requirement in order to recognize homozygous and heterozygous plant within a mutant. According to NASC background information, N671573, N668172, N679576 and N683883 were all considered to be homozygous lines. However, only four, two, one and four homozygous plants from five plants were detected from those mutants respectively. However, all plants from $\mathrm{N} 666896$ (described to be homozygous) were observed to show homozygous patterns. In regards to these differences, confirming at least one homozygous plant/mutant was necessary in order to provide enough seeds for further experiments. 


\subsection{Morphological study of mutants}

Due to the vital contribution of dioxygenase genes in several biological activities as stated previously, a single gene knock-out in every mutant can be valuable. Phenotypic variations in the mutants might result from changes in the ratios of endogenous hormones such as auxin/cytokinin (Kobayashi et al. 2012). In addition, proteins encoded by respective genes may influence aspects of particular metabolism including plant growth regulators such as gibberellin that promotes seed germination and internode elongation (Wang et al. 2013).

Moreover, phenotypic variations between plants within a mutant or between mutants may be a consequence of variations in the pathway of DNA/RNA damage/repair and posttranslational modifications (Hewitson et al. 2005) or from changes in important enzymatic activities causing significant changes in epigenetic markers (Aik et al. 2012). Future experiments may help to answer some questions regarding these morphological variations within and between mutants.

\section{References}

Aik, W., McDonough, M.A., Thalhammer, A., Chowdhury, R. and Schofield, C.J. (2012) Role of the jelly-roll fold in substrate binding by 2-oxoglutarate oxygenases. Current Opinion in Structural Biology, 22, 691-700.

Alberts, B., Johnson, A., Lewis, J., Martin, R., Roberts, K. and Watson, J. (2008) Molecular Biology of the Cell. $5^{\text {th }}$ ed: Garland Science. New York: USA.

Chen, Z.J. and Tian, L. (2007) Roles of dynamic and reversible histone acetylation in plant development and polyploidy. Biochimica et Biophysica Acta (BBA)-Gene Structure and Expression, 1769, 295-307.

Cheynier, V., Comte, G., Davies, K.M., Lattanzio, V. and Martens, S. (2013) Plant phenolics: recent advances on their biosynthesis, genetics, and ecophysiology. Plant Physiology and Biochemistry, 72, 1-20.

Cheynier, V., Comte, G., Davies, K.M., Lattanzio, V. and Martens, S. (2013) Plant phenolics: recent advances on their biosynthesis, genetics, and ecophysiology. Plant Physiology and Biochemistry, 72, 1-20.

Etchegaray, J.-P., Chavez, L., Huang, Y., Ross, K.N., Choi, J., Martinez-Pastor, B., Walsh, R.M., Sommer, C.A., Lienhard, M. and Gladden, A. (2015) The histone deacetylase SIRT6 controls embryonic stem cell fate via TET-mediated production of 5-hydroxymethylcytosine. Nature Cell Biology, 17, 545-557 
Geilen, K. and Böhmer, M. (2015) Dynamic subnuclear relocalisation of WRKY40 in response to Abscisic acid in Arabidopsis thaliana. Nature Scientific Reports, 5.

Grandperret, V., Nicolas-Francés, V., Wendehenne, D. and Bourque, S. (2014) Type-II histone deacetylases: elusive plant nuclear signal transducers. Plant, Cell \& Environment, 37, 12591269.

Hausinger, R.P. (2015) Biochemical diversity of 2-oxoglutarate-dependent oxygenases. in 2Oxoglutarate-Dependent Oxygenases (Hausinger, R. P., and Schofield, C. J. eds.): Cambridge, UK: The Royal Society of Chemistry. 1-58.

Hewitson, K., Granatino, N., Welford, R., McDonough, M. and Schofield, C. (2005) Oxidation by 2oxoglutarate oxygenases: non-haem iron systems in catalysis and signalling. Philosophical Transactions of the Royal Society of London A: Mathematical, Physical and Engineering Sciences, 363, 807-828.

Hewitson, K., Granatino, N., Welford, R., McDonough, M. and Schofield, C. (2005) Oxidation by 2oxoglutarate oxygenases: non-haem iron systems in catalysis and signalling. Philosophical Transactions of the Royal Society of London A: Mathematical, Physical and Engineering Sciences, 363, 807-828.

Jans, D.A., Xiao, C.Y. and Lam, M.H. (2000) Nuclear targeting signal recognition: a key control point in nuclear transport? Bioessays, 22, 532-544.

Kobayashi, T. and Nishizawa, N.K. (2012) Iron uptake, translocation, and regulation in higher plants. Annual Review of Plant Biology, 63, 131-152.

Lange, A., Mills, R.E., Lange, C.J., Stewart, M., Devine, S.E. and Corbett, A.H. (2007) Classical nuclear localization signals: definition, function, and interaction with importin $\alpha$. Journal of Biological Chemistry, 282, 5101-5105.

Lee, S., Doxey, A.C., McConkey, B.J. and Moffatt, B.A. (2012) Nuclear targeting of methylrecycling enzymes in Arabidopsis thaliana is mediated by specific protein interactions. Molecular Plant, 5, 231-248.

Martens, S., Preuß, A. and Matern, U. (2010) Multifunctional flavonoid dioxygenases: Flavonol and anthocyanin biosynthesis in Arabidopsis thaliana L. Phytochemistry, 71, 1040-1049.

Saito, K., Yonekura-Sakakibara, K., Nakabayashi, R., Higashi, Y., Yamazaki, M., Tohge, T. and Fernie, A.R. (2013) The flavonoid biosynthetic pathway in Arabidopsis: structural and genetic diversity. Plant Physiology and Biochemistry, 72, 21-34. 
Uji, T., Takahashi, M., Saga, N. and Mikami, K. (2010) Visualization of nuclear localization of transcription factors with cyan and green fluorescent proteins in the red alga Porphyra yezoensis. Marine Biotechnology, 12, 150-159.

Wang, J., Yu, Y., Zhang, Z., Quan, R., Zhang, H., Ma, L., Deng, X.W. and Huang, R. (2013) Arabidopsis CSN5B interacts with VTC1 and modulates ascorbic acid synthesis. The Plant Cell, 25, 625-636. 